\title{
Parotiditis: Una enfermedad inmunoprevenible que requiere atención
}

\author{
María L. Avila-Agüero ${ }^{1}$ y Ana Morice-Trejos²
}

\author{
Mumps: A Vaccine-preventable disease that requires attention
}

\section{$\mathrm{L}$}

a parotiditis es ocasionada por un virus ARN monocatenario perteneciente a la familia Paramyxoviridae, género Rubulavirus; un serotipo y 12 genotipos (A-L) lo componen ${ }^{1}$. A pesar de ser una enfermedad prevenible por vacunación, varios países a través de sus sistemas de vigilancia, han reportado un importante repunte de casos.

El análisis epidemiológico de la parotiditis en las Américas (Figura 1) según datos reportados a la Organización Mundial de la Salud (OMS), refleja la ocurrencia de brotes en países como México, El Salvador, Uruguay y Costa Rica, y una tendencia creciente en el reporte de casos en Chile, Paraguay, Colombia y Ecuador. Durante el período 2016-19, los Centers for Disease Control and Prevention ${ }^{2}$ reportaron 17,344 casos en los Estados Unidos de Norteamérica (E.U.A.). En Argentina, a partir de la introducción de la vacuna SRP en 1998, las tasas de parotiditis mostraron una reducción acelerada, pero en los últimos se observó una tendencia al incremento de casos. Costa Rica y El Salvador han reportado brotes en centros penitenciarios, que han sido difíciles de controlar ${ }^{3,4}$; paralelo a ello se han presentado casos en la comunidad. La edad de mayor incidencia se ha desplazado, afectando adolescentes y adultos jóvenes. En El Salvador, el brote del año 2019 evidenció una mayor tasa de ataque entre adultos de 20-49 años; datos similares reportó el Ministerio de Salud de Costa Rica, para el mismo año.

Los casos y los brotes se pueden atribuir a diferentes factores, entre ellos, bajas coberturas de vacunación, falla primaria o secundaria a la inmunización y descenso de los anticuerpos protectores con el paso del tiempo. Otro elemento es la correlación entre el genotipo vacunal y el genotipo circulante; por ejemplo, en Europa, varios genotipos circulantes han sido identificados: D, F, G, H y J. En la región de las Américas se ha descrito la circulación

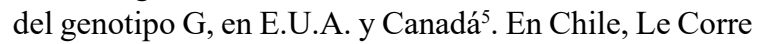
$\mathrm{N}$ y cols. ${ }^{6}$, reportan la circulación del genotipo $\mathrm{G}$ en dos adultos jóvenes.

Las vacunas utilizadas contienen genotipo A (Jeryl Lynn) o genotipo B (Urabe). El genotipo de la vacuna

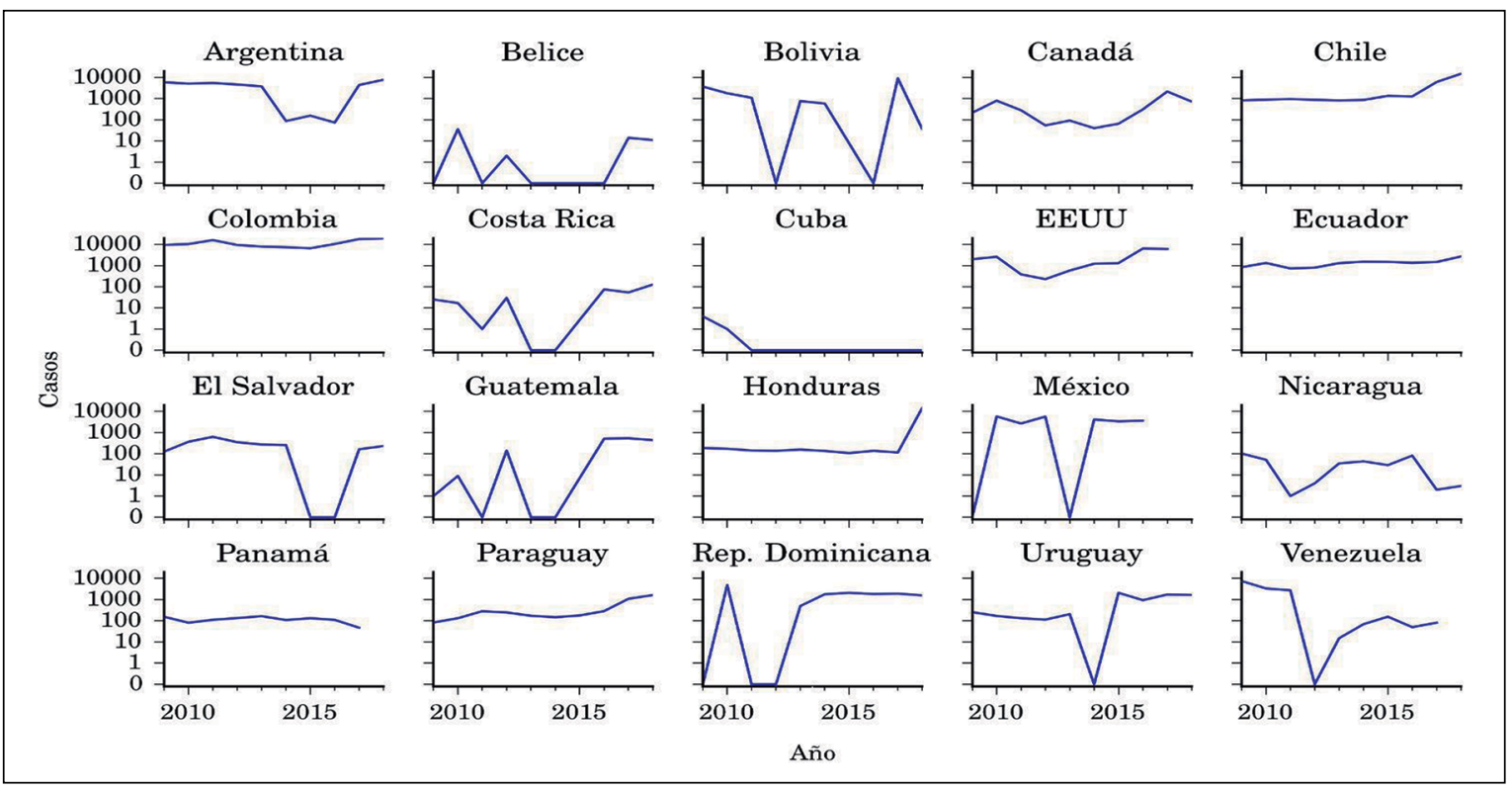

'Servicio de Infectología del Hospital Nacional de Niños, San José, Costa Rica. Investigadora Afiliada al Center for Modeling and Analysis of Infectious Diseases (CIDMA) of Yale University. ${ }^{2}$ Consultora Independiente. San José, Costa Rica.

Correspondencia a: María L. Avila-Agüero avilaaguero@gmail.com
Figura 1. Reporte de casos de parotiditis en la Región de las Américas 2010-2018. Fuente: Elaboración propia con datos de OMS. Escala logarítmica base 10 . 
Leningrado-Zagreb es el N. La eficacia vacunal debe ser considerada. Los primeros ensayos con la cepa de la vacuna Jeryl Lynn demostraron una eficacia cercana a $95 \%$, pero en condiciones epidémicas, la efectividad puede bajar a $62 \%$. La cepa de la vacuna Urabe tiene una efectividad de 54 a $87 \%$, pero es propensa a causar meningitis aséptica. La cepa de la vacuna LeningradoZagreb, que se usa ampliamente en los países en desarrollo parece tener una efectividad superior a $95 \%$.

Para finales del 2018, la OMS reportó que la vacuna contra la parotiditis se había introducido en 122 países $(62,8 \%)$ del total de 194 Estados miembros ${ }^{8}$. Aún así, a nivel global muchos países aún no vacunan contra la parotiditis y el virus continúa circulando. Por el contrario, en las Américas, todos los países han incorporado dos dosis de la vacuna triple viral (sarampión-rubéola-parotiditis: SRP 2018) en el programa de rutina, alcanzando una cobertura regional de $91 \%$ para SRP1 y $83 \%$ para SRP2, pero al interior de los países las coberturas no son homogéneas a nivel distrital ${ }^{9}$. Por otro lado, muchas de las campañas de seguimiento han utilizado vacuna doble viral, contra sarampión y rubéola, sin el componente parotiditis.

A la fecha, se recomiendan dos dosis de vacuna SRP, la primera entre los 12-15 meses, y la segunda entre 4 y 6 años. En América Latina, en el año 2013 el TAG (Grupo Técnico Asesor) de la OPS recomendó adelantar la edad de administración de la segunda dosis a los 18 meses, pero en la actualidad los grupos-objetivo de la segunda dosis de SRP difieren entre países pues sólo algunos programas de vacunación implementaron esa recomendación ${ }^{10}$.

La segunda dosis de la vacuna se implementó para “optimizar" la respuesta inmune y aumentar la proporción de individuos que exhiben anticuerpos. Sin embargo, Lewnard y $\mathrm{Grad}^{11}$, publican un meta-análisis donde se evidencia que la segunda dosis sólo restaura la inmunidad hasta el nivel de la primera. Algunos autores han postulado la necesidad de una tercera dosis durante la adolescencia, pero a los 12 meses de esa dosis, los titulos de anticuerpos eran similares que previo al refuerzo ${ }^{12}$. Es posible que una tercera dosis, sí sea efectiva en condiciones de brote.

Los brotes de parotiditis y tendencias al incremento del reporte de casos en algunos países deben llamar a la acción ya que, al igual que otras enfermedades infantiles, la gravedad de la parotiditis aumenta con la edad. Los hombres exhiben un riesgo notablemente mayor de sufrir complicaciones a una edad más alta que las mujeres. La probabilidad de desarrollar orquitis se calculó en $25 \%$ para los hombres después de la pubertad, con el consiguiente riesgo de infertilidad ${ }^{13}$. Han sido reportadas otras complicaciones como meningitis aséptica y sordera. Además, brotes en centros de privados de libertad, universidades o entre población migrante, son dificiles de controlar y tienen un costo económico elevado.

En conclusión, la incorporación de la vacuna SRP provocó una disminución en la incidencia de casos de parotiditis, pero durante los últimos años se observa un incremento en el reporte de casos y la ocurrencia de brotes. Se requiere mejorar la vigilancia, tener una mejor caracterización epidemiológica de los casos, incluyendo población de riesgo, genotipos circulantes, y sobre todo elegir la mejor estrategia para reducir el riesgo y dar una respuesta efectiva ante la ocurrencia de brotes.

\section{Referencias bibliográficas}

1.- Hviid A, Rubin S, Mühlemann K. Mumps. Lancet 2008; 371 (9616): 932-44. doi: 10.1016/ S0140-6736(08)60419-5.

2.- CDC https://www.cdc.gov/mumps/outbreaks. html. Mumps Cases and Outbreaks.

3.- Boletín Epidemiológico Servicios de Salud Penitenciarios. Ministerio de Justicia y Paz / Ministerio de Salud Noviembre 2019.

4.- Boletín Epidemiológico Ministerio de Salud / Dirección Vigilancia Sanitaria El Salvador 2019.

5.- Stapleton P J, Eshaghi A, Seo C Y, Wilson S, Harris T, Deeks S L, et al. Evaluating the use of whole genome sequencing for the investigation of a large mumps outbreak in Ontario, Canada. Sci Rep 2019; 9: 12615. https://doi. org/10.1038/s41598-019-47740-1.

6.- Le Corre N, Barría S, López T, MartínezValdebenito C, Contreras AM, Ferrés M.
Parotiditis en Chile: caracterización clínica y molecular de dos casos en una población altamente inmunizada Rev Chilena Infectol 2018; 35 (2): 198-203. http://dx.doi. org/10.4067/s0716-10182018000200198.

7.- Peltola H, Kulkarni P S, Kapre S V, Paunio M, Jadhav S S, Dhere R M. Mumps outbreaks in Canada and the United States: time for new thinking on mumps vaccines. Clin Infect Dis 2007; 45 (4): 459-66. doi: 10.1086/520028.

8.- Organización Mundial de la Salud. Immunization coverage: Key Facts. https:// www.who.int/en/news-room/fact-sheets/detail/ immunization-coverage.

9.- Pan American Health Organization. Immunization in the Americas: 2019 Summary. Washington DC: PAHO, 2019. https:// www.paho.org/hq/index.php?option=com docman\&view=download\&category_ slug=brochures-immunization1581\&alias $=50553$-immunization- in-the-americas-2019summary\& Itemid $=270 \&$ lang $=$ en

10.- OMS-OPS Formulario conjunto para la notificación de inmunizaciones de la OMS-OPS y UNICEF JRF 2018.

11.- Lewnard J A, Grad Y H. Vaccine waning and mumps re-emergence in the United States. Sci. Transl. Med. 2018, 10 (433). Pii: eaao5945. doi: 10.1126/scitranslmed.aao5945.

12.- Cardemil C V, Dahl R M, James L, Wannemuehler K, Gary H E, Shah M, et al. Effectiveness of a third dose of MMR vaccine for mumps outbreak control. N Engl J Med 2017; 377: 947-56. doi: 10.1056/ NEJMoa1703309

13.- Anderson R M, Crombie J A, Grenfell B T. The epidemiology of mumps in the UK A preliminary study of virus transmission, herd immunity and the potential impact of immunization. Epidemiol Infect 1987; 99: $65-$ 84. doi: $10.1017 / \mathrm{s} 0950268800066875$. 